\title{
A survey of canine tick-borne diseases in India
}

\author{
Puteri Azaziah Megat Abd Rani ${ }^{1,4^{*}}$, Peter J Irwin², Glen T Coleman ${ }^{1}$, Mukulesh Gatne $^{3}$ and Rebecca J Traub ${ }^{1}$
}

\begin{abstract}
Background: There are few published reports on canine Babesia, Ehrlichia, Anaplasma, Hepatozoon and haemotropic Mycoplasma infections in India and most describe clinical disease in individual dogs, diagnosed by morphological observation of the microorganisms in stained blood smears. This study investigated the occurrence and distribution of canine tick-borne disease (TBD) pathogens using a combination of conventional and molecular diagnostic techniques in four cities in India.

Results: On microscopy examination, only Hepatozoon gamonts were observed in twelve out of 525 (2.3\%; 95\% Cl: $1.2,4)$ blood smears. Using polymerase chain reaction (PCR), a total of 261 from 525 dogs (49.7\%; 95\% Cl: 45.4, 54.1 ) in this study were infected with one or more canine tick-borne pathogen. Hepatozoon canis (30\%; 95\% Cl: 26.0, 34.0) was the most common TBD pathogen found infecting dogs in India followed by Ehrlichia canis (20.6\%; 95\% Cl: 17.2, 24.3), Mycoplasma haemocanis (12.2\%; 95\% Cl: 9.5, 15.3), Anaplasma platys (6.5\%; 95\% Cl: 4.5, 8.9), Babesia vogeli $(5.5 \%, 95 \% \mathrm{Cl}: 3.7,7.8)$ and Babesia gibsoni (0.2\%, 95\% Cl: $0.01,1.06)$. Concurrent infection with more than one TBD pathogen occurred in 39\% of cases. Potential tick vectors, Rhipicephalus (most commonly) and/or Haemaphysalis ticks were found on 278 (53\%) of dogs examined.

Conclusions: At least 6 species of canine tick-borne pathogens are present in India. Hepatozoon canis was the most common pathogen and ticks belonging to the genus Rhipicephalus were encountered most frequently. Polymerase chain reaction was more sensitive in detecting circulating pathogens compared with peripheral blood smear examination. As co-infections with canine TBD pathogens were common, Indian veterinary practitioners should be cognisant that the discovery of one such pathogen raises the potential for multiple infections which may warrant different clinical management strategies.
\end{abstract}

\section{Background}

There is a relative paucity of studies into canine Babesia, Ehrlichia, Anaplasma, Hepatozoon and haemotropic Mycoplasma infections in India and most cases of canine tick-borne diseases (TBD) reported from the Indian subcontinent have been diagnosed by traditional methods using microscopic observation of microorganisms in stained blood smears [1]. This approach, based on morphological characteristics, does not permit reliable identification of the parasites. Serological approaches also have their limitations particularly as species-specific diagnosis is often required; both false positive [2,3] and false negative results [4] may confound interpretation. Since pathogenicity is known to vary significantly depending on the species of TBD

\footnotetext{
* Correspondence: puteri.megatabdrani@uqconnect.edu.au

'School of Veterinary Science, The University of Queensland, Gatton,

Queensland, Australia

Full list of author information is available at the end of the article
}

pathogen [5], it is preferable to use molecular-based tools to investigate the clinical significance of canine TBD in India.

Babesiosis is an important disease of domestic and wild Canidae in Asia but the epidemiology of canine babesiosis in India is poorly understood. In a large study conducted in Chennai, Babesia gibsoni was reported with a prevalence of $0.1 \%$ [6] in client-owned dogs $(n=$ 5,832 ) using bloods smear evaluation only. Other studies report $9 \%$ and $22 \%$ of dogs in Uttar Pradesh [7] and Assam [8], respectively, infected with Babesia, but the species of piroplasm infecting these dogs was not reported. The pathogenicity of Babesia is believed to vary in different regions of India and this is likely due to host factors and/or differences in the species present [1]. It is likely that both Babesia vogeli and B. gibsoni are co-endemic in India and the ticks Rhipicephalus sanguineus and Haemaphysalis longicornis are the putative vectors, respectively [5]. 
Ehrlichia is an alpha-proteobacterium belonging to the family Anaplasmataceae. Species that are able to produce infection in dogs are Ehrlichia canis (tropical canine pancytopenia), Ehrlichia ewingii (canine granulocytic ehrlichiosis) and Ehrlichia chaffeensis (human monocytic ehrlichiosis) $[9,10]$. The few studies investigating the prevalence of canine ehrlichiosis in India using conventional examination of stained blood smears have reported prevalences of $0.35 \%(\mathrm{n}=752)$ in Punjab [11], $18.9 \%$ in Nagpur $(\mathrm{n}=238)$ [12] and 55\% in stray dogs in Maharashtra [13]. One study utilizing an E. canis-specific nested PCR found 46/98 (46.9\%) owned dogs in Chennai positive for Ehrlichia spp. compared to $19 \%$ by microscopy [14]. In this study however, amplicons were not sequenced to confirm the ehrlichial species and information about the clinical status of these dogs was also not reported.

Canine hepatozoonosis ranges from subclinical infections caused by Hepatozoon canis to severe, life-threatening disease caused by Hepatozoon americanum [15]. Transmission of $H$. canis to dogs occurs by ingestion of an infected tick, $R$. sanguineus, rather than tick bites [16]. Canine hepatozoonosis caused by $H$. canis has been reported most frequently as a subclinical infection in the north-west region of India, with a prevalence range of 3 to $9 \%$ in Punjab [17-19]. In other parts of the world, coinfection of $H$. canis with other infectious agents such as Ehrlichia, Leishmania and parvovirus is common [20-22].

Canine anaplasmosis is caused by intracellular rickettsial organisms of the genus Anaplasma. To date, two species have been identified as pathogenic in dogs; Anaplasma platys is the cause of canine infectious cyclic thrombocytopenia, and Anaplasma phagocytophilum, which parasitizes neutrophils, is zoonotic and causes granulocytic anaplasmosis in many countries in the northern hemisphere [22,23]. Single infections with $A$. platys are generally clinically unapparent but pathogenicity appears to be increased in co-infections [24].

Haemoplasmas are epierythrocytic parasites of mammals. Two species, Mycoplasma haemocanis and Candidatus Mycoplasma haematoparvum have been reported in dogs and the clinical effect of these microorganisms varies from asymptomatic infections to the induction of a severe haemolytic syndrome, especially in splenectomised or immunocompromised dogs $[25,26]$. Clinical disease caused by haemotropic Mycoplasma infections [27] and A. platys [28] have been reported in India but the prevalence and distribution of these pathogens remains largely unexplored.

This study was designed to investigate the occurrence and geographical distribution of canine TBD of veterinary and public health importance in India using a combination of conventional and molecular diagnostic techniques, and to examine associations between climatic and host-based risk factors and the presence of the various tick-borne diseases.

\section{Methods \\ Animal data}

Capillary and whole blood samples were collected from the cephalic and/or jugular veins of 525 dogs. Dogs were sampled at four sites, chosen to reflect the different climatic zones of India (Figure 1); Sikkim (subtropical highland) in northern West Bengal, Ladakh (montane region) in Jammu Kashmir, Delhi (monsooninfluenced humid subtropical region) and Mumbai (tropical region) [29], from June to September 2008. Sikkim and Ladakh are rural villages. To facilitate the fieldwork, collaborations were established with several locallybased partners; Vets Beyond Borders (VBB), Jeevaashram, Krishnaashram, Bombay Veterinary College (Mumbai) and In Defence of Animals India (IDAI). These organisations permitted us study access to stray and refuge dogs through their Animal Birth Control (ABC) and rabies vaccination programs, in which stray dogs are impounded, vaccinated, surgically neutered and released back to their original location. The refuge centres provide shelter, de-sexing and veterinary care where appropriate, for dogs that are either rescued from the streets or abandoned by their owners.

An estimate of each animal's age was made (based on dentition and body size) and classified as puppy (less than 6 months old), juvenile (between 6 months to 1 year old), adult (between 1 to 7 year old) and geriatric (more than 7 year old). Each animal's sex, body condition score and source (stray or refuge) [30] were noted, and the presence or absence of ticks was also recorded by searching the skin and hair coat of each dog for 1 minute. When present, a minimum of two ticks was collected and stored in $70 \%$ ethanol solution for later identification to genus level using Walker keys [31]. Body condition score (BCS) was determined using a 9-integer scale system [32]. All dogs were classified as apparently healthy or unwell based on their demeanour at the time of sampling, but a detailed clinical examination was not performed.

Blood smears were made from whole blood and buffycoat preparations [33], air-dried and fixed in 100\% ethanol and later stained with Giemsa for microscopic screening. Packed cell volume (PCV) was measured using a microhaematocrit centrifuge. Blood samples were also applied to Whatmans FTA cards ${ }^{\circledR}$ for molecular-based screening. Microscope screening methodology and DNA extraction techniques have been described in detail previously [29].

\section{PCR assays and DNA sequencing}

Nested PCR assays with primers targeting the partial region of the 18S rRNA gene were used for detection of 


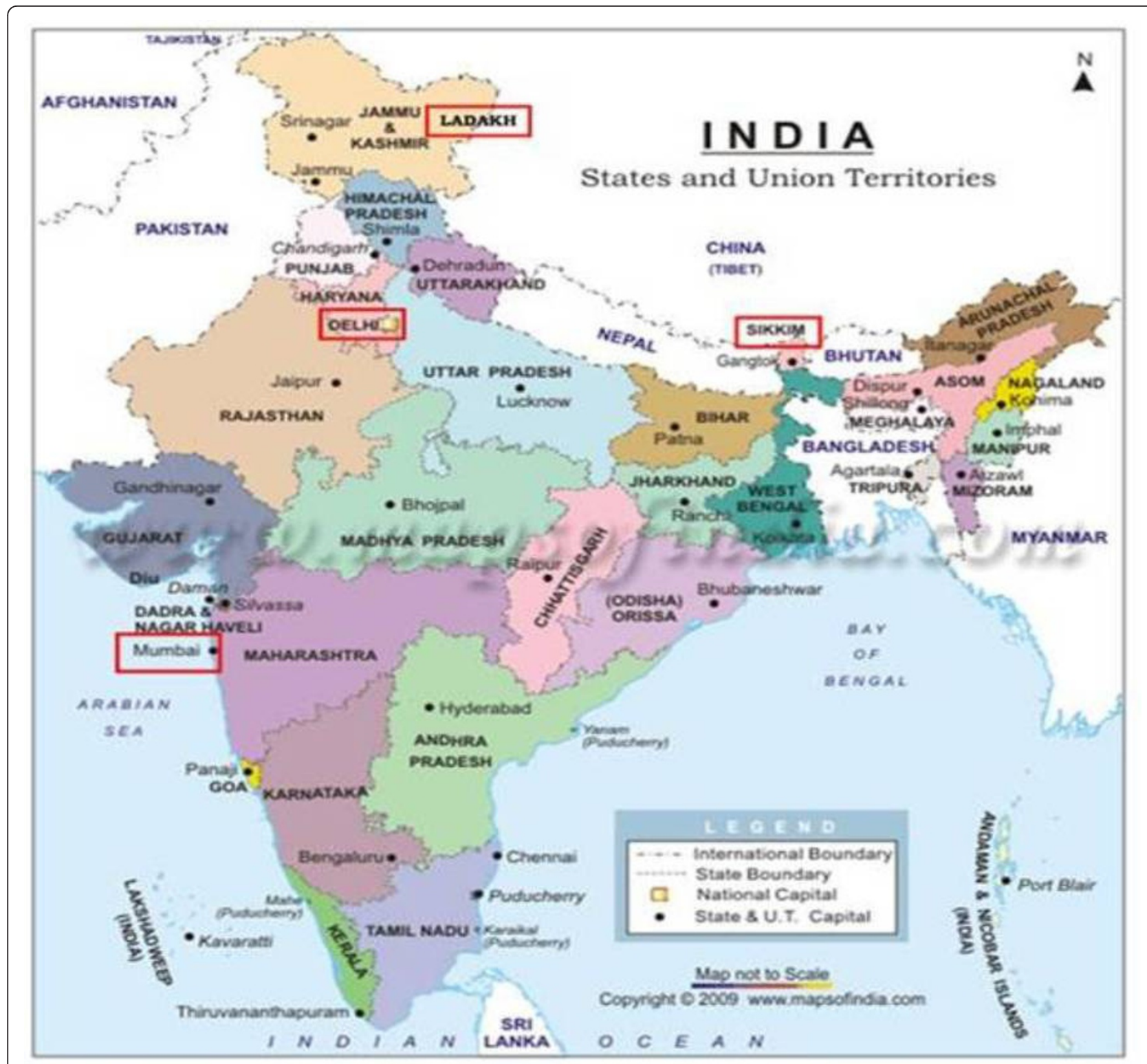

Figure 1 Map of India. Areas outlined in red rectangles indicate sampling locations.

canine piroplasm (Babesia, Theileria) species [34]. DNA amplification was performed under the conditions described by Jefferies and colleagues [34].

Touchdown PCR technique with ECA and HE3 primers [35] were used to amplify an approximate $400 \mathrm{bp}$ fragment of $16 \mathrm{~S}$ rRNA region of $E$. canis using conditions described by Gal and colleagues [36].

Forward primer, Platys and reverse primer EHR16SR [37] were used to amplify a partial region of the $16 \mathrm{~S}$ rRNA gene of $A$. platys under the following conditions: $95^{\circ} \mathrm{C}$ for $5 \mathrm{~min} ; 40$ cycles of $94^{\circ} \mathrm{C}$ for $30 \mathrm{~s}, 55^{\circ} \mathrm{C}$ for $30 \mathrm{~s}$, and $72^{\circ} \mathrm{C}$ for $90 \mathrm{~s}$; then final extension at $72^{\circ} \mathrm{C}$ for 5 $\min$.
For the detection of Hepatozoon, PCR was performed using primers HEP-F and HEP-R [38] under the following conditions: $95^{\circ} \mathrm{C}$ for $5 \mathrm{~min} ; 40$ cycles of $95^{\circ} \mathrm{C}$ for 30 s, $57^{\circ} \mathrm{C}$ for $30 \mathrm{~s}$, and $72^{\circ} \mathrm{C}$ for $90 \mathrm{~s}$; then final extension at $72^{\circ} \mathrm{C}$ for $5 \mathrm{~min}$.

PCR detection of haemotropic Mycoplasma was performed using universal Mycoplasma spp. primers HBT$\mathrm{F}$ and HBT-R [39] under the following conditions: $94^{\circ} \mathrm{C}$ for $5 \mathrm{~min} ; 40$ cycles of $95^{\circ} \mathrm{C}$ for $30 \mathrm{~s}, 60^{\circ} \mathrm{C}$ for $30 \mathrm{~s}$, and $72^{\circ} \mathrm{C}$ for $90 \mathrm{~s}$; then final extension at $72^{\circ} \mathrm{C}$ for $10 \mathrm{~min}$.

The PCR products were run on a $2 \%$ agarose gel in 1 $\times$ TAE buffer at $100 \mathrm{~V}$ and visualised using GelDoc (Biorad). A randomly selected subset of products from 
$20 \%$ of the positive samples for each PCR protocol (Table 1) were purified using Qiagen spin columns (Qiagen) and sequenced using an ABI 3130xl Genetic Analyzer (Applied Biosystems) with Big Dye 3.0 chemistry. Sequences were edited and assembled using Finch TV (Geospiza Inc.) and compared to sequence data on GenBank using the Blast program (http://blast.ncbi.nlm.nih. gov/Blast.cgi) to confirm results.

\section{Statistical analysis}

The prevalence and 95\% binomial exact confidence intervals $(\mathrm{CI})$ were calculated for the microscopy and PCR results for each TBD pathogen using Sourceforge. net $^{\circledR}$ (http://sampsize.sourceforge.net/iface/index.html). Association between canine TBD, host factors (age, gender, and source) and geographical location were evaluated using univariate analyses of odd ratios and their 95\% confidence intervals using Chi-square test or Fisher's exact test for independence. Continuous data was analysed using one-way analysis of variance (ANOVA). Statistical significance was set at $\mathrm{p} \leq 0.025$. Multivariate logistic regression was used where data was substantial enough to quantify the association between the presence of vector-borne disease and host and climate variables after adjusting for other variables. Only variables significant at $\mathrm{p} \leq 0.25$ in the univariate analyses were considered eligible for inclusion in the multiple regression $[40,41]$. Backward elimination was used to determine which factors could be dropped from the multivariate model. The level of significance for a factor to remain in the final model was set at $5 \%$. Statistical calculations were conducted using SPSS version 19.0 software (SPSS Inc., Chicago, IL, USA).

\section{Results}

A total of 525 dogs, consisting of $42.1 \%$ intact females, $35.1 \%$ intact males, $12.3 \%$ neutered males and $10.5 \%$ neutered females were sampled; $77 \%$ were strays and
$23 \%$ were shelter dogs. Upon visual inspection, 278 (53\%) dogs were infested with ticks. The highest tick infestation was noted in Mumbai (prevalence 80\%; $\mathrm{n}=$ 162) followed by Delhi, (prevalence 75.3\%; $n=162$ ); Sikkim (prevalence 17\%; $\mathrm{n}=101$ ) and Ladakh (prevalence $11 \% ; n=100)$. A total of 832 ticks was collected and identified; the genus Rhipicephalus was found to be the most common dog tick present in this study followed by Haemaphysalis. The prevalence of tick genera by city are presented in Table 2.

Body condition scores (BCS) were recorded for 521 dogs. Scores were normally distributed; the mean \pm SD $\mathrm{BCS}$ was $3.83 \pm 1.12$; the mode BCS was 3 . Most dogs examined were adults (80\%), followed by juveniles $(9.2 \%)$, geriatrics $(8.8 \%)$ and puppies $(1.7 \%)$. All dogs were apparently healthy, except one that was found to be moribund due to a recent automobile accident. Packed cell volumes were reported for 441 dogs. The mean \pm SD for PCV was $32.67 \% \pm 8.9$.

Blood smear examination of every sample was negative for Babesia, Ehrlichia, Anaplasma and haemotropic Mycoplasma spp., whereas Hepatozoon gamonts were observed in twelve (2.3\%; 95\% CI: 1.02, 3.58) samples. In contrast, using PCR, nearly half (261/525 or $49.7 \%$; $95 \%$ CI: $45.4,54.1)$ the dogs in this study were found to be infected with one or more canine TBD pathogens. All sequenced PCR amplicons were confirmed by comparison with published sequences on GenBank and matched with $99-100 \%$ homology. Of the 261 PCR positive dogs, 160 (61.3\%; 95\% CI: 55.1, 67.2) had single infections. Multiple infections with two or more canine TBD pathogens were found only in dogs from Delhi and Mumbai; 75 (28.7\%; 95\% CI: 23.3, 34.6) were co-infected with two, 22 (8.5\%; 95\% CI; 5.4, 12.5) with three and 4 (1.5\%; 95\% CI: 0.4, 3.9) with four species of canine TBD pathogens. Among 101 dogs that were positive for multiple infections, 50 (49.5\%; 95\% CI: 39.4, 59.6) were coinfected with $H$. canis and $E$. canis. The occurrence of

Table 1 Primer sets for the PCR amplification and sequencing of canine TBD pathogens used in this study.

\begin{tabular}{|c|c|c|}
\hline & Primers & Reference \\
\hline \multirow[t]{4}{*}{ Babesia species } & BTF1: 5'-GGC TCA TTA CAA CAG TTA TAG-3' & {$[34]$} \\
\hline & BTR1: 5'-CCC AAA GAC TTा GAT TTC TCT C-3' & \\
\hline & BTF2: 5'-CCG TGC TAA TTG TAG GGC TAA TAC-3' & \\
\hline & BTR2: 5'-GGA CTA CGA CGG TAT CTG ATC G-3' & \\
\hline \multirow[t]{2}{*}{ Ehrlichia canis } & ECA: 5'-AAC ACA TGC AAG TCG AAC GGA-3' & {$[36]$} \\
\hline & HE3: 5'-TAT AGG TAC CGT CAT TAT CTT CCC TAT-3' & \\
\hline \multirow[t]{2}{*}{ Hepatozoon species } & HEP-F: 5'-ATA CAT GAG CAA AAT CTC AAC-3' & {$[38]$} \\
\hline & HEP-R: 5'-CTT ATT ATT CCA TGC TGC AG-3' & \\
\hline \multirow[t]{2}{*}{ Anaplasma platys } & Platys: 5'-GAT TTT TGT CGT AGC TTG CTA TG-3' & {$[37]$} \\
\hline & EHR16SR: 5'TAG CAC TCA TCG TाT ACA GC-3' & \\
\hline \multirow[t]{2}{*}{ Mycoplasma species } & HBT-F: 5'-ATA CGG CCC ATA TTC CTA CG-3' & {$[39]$} \\
\hline & HBT-R: 5'-TGC TCC ACC ACT TGT TCA-3' & \\
\hline
\end{tabular}


Table 2 Prevalence of tick genera infecting dogs by sampling location

\begin{tabular}{lllll}
\hline Tick genera & $\begin{array}{l}\text { Mumbai } \\
(\mathbf{n}=\mathbf{4 1 7})\end{array}$ & $\begin{array}{l}\text { Delhi } \\
(\mathbf{n}=\mathbf{3 7 9})\end{array}$ & $\begin{array}{l}\text { Sikkim } \\
(\mathbf{n}=\mathbf{2 8})\end{array}$ & $\begin{array}{l}\text { Ladakh } \\
(\mathbf{n}=\mathbf{8})\end{array}$ \\
\hline Rhipicephalus spp. & $100 \%$ & $100 \%$ & $44.4 \%$ & $100 \%$ \\
Haemaphysalis spp. & $0 \%$ & $0 \%$ & $55.6 \%$ & $0 \%$ \\
\hline
\end{tabular}

canine TBD pathogens by molecular screening is summarised in Table 3 and Table 4.

\section{Risk factor analysis}

There was a significant relationship between location and canine TBD infection $\left(\chi^{2} 124.5, \mathrm{df}=3, \mathrm{p}<0.01\right)$, which in turn was highly correlated with the presence of ticks on dogs $(\mathrm{p}<0.01)$. Dogs in Delhi and Mumbai were more likely to be infected with ticks and TBD pathogens compared to those from Ladakh and Sikkim. Dogs infected with one or more canine TBD pathogens had a lower PCV (average 29.7\%) compared to noninfected dogs (average 35.8\%, $\mathrm{p}<0.01$ ). Multivariate risk factor analysis $\left(R^{2}=0.197\right)$ revealed that that dogs infested with ticks were 3.3 (95\% CI:2.2, 4.8) times more likely be PCR positive for at least one or more canine TBD pathogen than dogs without tick infestation $(\mathrm{p}<$ 0.01), that neutered dogs were 1.9 (95\% CI:1.1, 3.4) times less likely to be PCR positive for canine TBDs compared to intact dogs $(\mathrm{p}=0.02)$ and that dogs from refuges were $2.3(95 \% \mathrm{CI}: 1.3,3.9)$ times less likely to be PCR positive for canine TBDs compared to stray dogs $(\mathrm{p}<0.01)$. No significant association with age, sex or body score condition with infection was found for any of the parasites.

\section{Discussion}

Despite previous single case reports, to the authors' knowledge this study is the first systematic investigation of the prevalence and diversity of canine TBDs in the regions of Delhi, Mumbai, Sikkim and Ladakh in India using both microscopy and molecular techniques. The study has provided interesting new information about canine TBD, but further investigation using larger numbers of dogs from more localities is necessary in order
Table 4 The occurrence of co-infections with canine TBD by city

\begin{tabular}{lcc}
\hline Pathogen species & $\begin{array}{c}\text { Delhi } \\
(\mathbf{n}=\mathbf{5 7})\end{array}$ & $\begin{array}{c}\text { Mumbai } \\
(\mathbf{n}=\mathbf{4 4})\end{array}$ \\
\hline $\mathbf{B}+\mathbf{E}$ & $7 \%$ & $0 \%$ \\
$\mathbf{B}+\mathbf{H}$ & $7 \%$ & $13.6 \%$ \\
$\mathbf{B}+\mathbf{A}$ & $1.8 \%$ & $0 \%$ \\
$\mathbf{E}+\mathbf{H}$ & $28 \%$ & $36.4 \%$ \\
$\mathbf{E}+\mathbf{A}$ & $7 \%$ & $4.5 \%$ \\
$\mathbf{E}+\mathbf{M}$ & $14 \%$ & $2.3 \%$ \\
$\mathbf{H}+\mathbf{A}$ & $3.5 \%$ & $4.5 \%$ \\
$\mathbf{H}+\mathbf{M}$ & $5.3 \%$ & $13.6 \%$ \\
$\mathbf{B}+\mathbf{E}+\mathbf{H}$ & $0 \%$ & $4.5 \%$ \\
$\mathbf{B}+\mathbf{H}+\mathbf{A}$ & $0 \%$ & $2.3 \%$ \\
$\mathbf{B}+\mathbf{H}+\mathbf{M}$ & $1.8 \%$ & $2.3 \%$ \\
$\mathbf{E}+\mathbf{H}+\mathbf{A}$ & $5.3 \%$ & $0 \%$ \\
$\mathbf{E}+\mathbf{H}+\mathbf{M}$ & $8.7 \%$ & $9.2 \%$ \\
$\mathbf{E}+\mathbf{A}+\mathbf{M}$ & $3.5 \%$ & $0 \%$ \\
$\mathbf{H}+\mathbf{A}+\mathbf{M}$ & $1.8 \%$ & $4.5 \%$ \\
$\mathbf{E}+\mathbf{H}+\mathbf{A}+\mathbf{M}$ & $5.3 \%$ & $2.3 \%$ \\
\hline B & &
\end{tabular}

B: Babesia vogeli

E: Ehrlichia canis

$\mathrm{H}$ : Hepatozoon canis

A: Anaplasma platys

M: Mycoplasma haemocanis

to gain a truly comprehensive understanding of the distributions of these diseases in India.

Unsurprisingly, the occurrences of both ticks and TBDs in dogs were shown to be higher in Delhi and Mumbai compared to Ladakh and Sikkim. This most likely reflects their different climates, with the former pair being subtropical and tropical, respectively, compared with Ladakh which at significant altitude (3000 $\mathrm{m})$ is arid and dry, and Sikkim which enjoys a more temperate climate. The genus Rhipicephalus was found to be the most common tick present in this study followed by Haemaphysalis. In this study, ticks were identified morphologically to genus level only. Interestingly, Haemaphysalis ticks were identified only in Sikkim, in just over half of the dogs, which again most likely reflects the prevailing climatic conditions of the region that are more suitable ecologically for this genus [42-44]

Table 3 The prevalence (\%) and $95 \% \mathrm{Cl}$ (lower, upper intervals) of canine tick-borne disease pathogens by city using molecular screening.

\begin{tabular}{|c|c|c|c|c|}
\hline & $\begin{array}{c}\text { Delhi } \\
(n=162)\end{array}$ & $\begin{array}{l}\text { Mumbai } \\
(n=162)\end{array}$ & $\begin{array}{c}\text { Sikkim } \\
(n=101)\end{array}$ & $\begin{array}{l}\text { Ladakh } \\
(n=100)\end{array}$ \\
\hline Babesia vogeli & $8.6 \%(4.8,14.1)$ & $7.4 \%(3.9,12.6)$ & $2 \%(0.6,8.4)$ & $0 \%(0,3.6)$ \\
\hline Babesia gibsoni & $0 \%(0,2.3)$ & $0 \%(0,2.3)$ & $1 \%(0.03,5.4)$ & $0 \%(0,3.6)$ \\
\hline Hepatozoon canis & $38.3 \%(30.8,46.2)$ & $43.8 \%(36.1,51.8)$ & $0 \%(0,3.6)$ & $24 \%(16,33.6)$ \\
\hline Ehrlichia canis & $39.5 \%(31.9,47.5)$ & $27.2 \%(20.5,34.7)$ & $0 \%(0,3.6)$ & $0 \%(0,3.6)$ \\
\hline Anaplasma platys & $13 \%(8.2,19.1)$ & $8 \%(4.3,13.3)$ & $0 \%(0,3.6)$ & $0 \%(0,3.6)$ \\
\hline Mycoplasma haemocanis & $17.3 \%(11.8,24)$ & $14.2 \%(9.2,20.5)$ & $1 \%(0.03,5.4)$ & $12 \%(6.4,20)$ \\
\hline
\end{tabular}


than the other hotter or drier areas of India where sampling was performed. Haemaphysalis ticks have been reported previously in the rural highland areas of India such as Jammu Kashmir, Himanchal Pradesh and Arunanchal Pradesh [44], and a study in Japan also revealed that dogs in rural areas carried more Haemaphysalis ticks. In contrast Rhipicephalus is often associated with dogs in urban areas [45], which is reflected by our findings that Rhipicephalus was more common in urban Mumbai and Delhi, compared to rural Sikkim.

In this study $H$. canis was the most common canine TBD pathogen found infecting dogs in India followed by E. canis, M. haemocanis and A. platys. This finding probably reflects the wide geographical distribution of their vector, $R$. sanguineus [46]. In contrast, $B$. vogeli and $B$. gibsoni were detected in fewer dogs. Although it is known that infection with either of these pathogens can result in severe and fatal disease, they can remain clinically undetectable in chronically infected dogs due to very low and often intermittent parasitaemias. Infection with these pathogens may not be apparent or diagnosed until such animals are immunocompromised by unrelated disease or by iatrogenic drug administration or following splenectomy $[2,47]$.

Since the advent of molecular diagnostic testing, it has become increasingly apparent that co-infections of canine TBD are common in other regions of the world $[5,22,28,48,49]$ and this study strongly suggests that the same is true in dogs in India. A recent experimental study reported that co-infection with $A$. platys and $E$. canis can influence various pathophysiological parameters in dogs [24] and supports the notion that multiple infections by canine TBD pathogens may lead to variable and sometimes unexpected clinical outcomes in individuals $[5,22,28,48,49]$. This is of significant clinical importance as multiple infections in the same host may go undiagnosed, especially if conventional methodology is used, thus frustrating attempts by the veterinary practitioner to adequately treat the individual. Whilst the diagnosis of these diseases is still challenging, a greater awareness of the possibility of canine TBD co-infection is necessary, particularly if poor or partial response to treatment targeting a single agent is observed.

In this study, the prevalence of TBD pathogens in dogs was shown to be positively correlated with the presence of ticks on the animal. However, in addition to this, TBD were less likely to infect dogs from refuges and in those animals that were neutered, even after adjusting for the presence of ticks. This implies that other possibly host- and environmental factors may play an important role in the epidemiology of TBD in dogs. Dogs housed in shelters (refuge dogs) and fed nutritious diets are likely to have a more robust immune status than free roaming strays. Similarly, the hormones oestrogen and testosterone are known to influence the outcome of infectious diseases and this has been widely discussed with respect to parasite infections in humans and non-primate hosts [50,51]. For example, one study reported that the prevalence of intestinal parasites was higher in male dogs and that gonadectomy decreased the likelihood of parasitism in both male and female dogs [52]. In addition to potentially controlling the dog population, de-sexing animals may therefore have a beneficial immuno-protective role for the canine TBD.

In a finding that is now well recognised in epidemiological surveys, the molecular techniques used in this study were shown to be highly sensitive compared to microscopic examinations. Examining stained blood smears is time consuming and requires some level of technical expertise. Often it is not very rewarding as the pathogen is either absent or present in very low numbers; intermittent low parasitaemia is a feature of chronic canine TBD infection [53,54] and poses a significant problem when trying to detect carrier individuals. Thus, the negative findings by microscopic examination in this study were not surprising since none of the dogs showed any evidence of clinical signs. However, blood smear examination remains the simplest and most accessible diagnostic test for veterinarians, to use and is reasonably sensitive during acute, clinically significant infections. Molecular and serological techniques are more useful for detecting chronic and subclinical infections, and are ideally suited to epidemiological investigations as reported here. Despite numerous efforts to optimize PCR screening, because of the nature of these pathogens, a negative result should be interpreted with caution. The combination of haematology, cytology, serology and molecular diagnoses is needed to finalise any screening process to avoid misdiagnoses.

\section{Conclusion}

At least 6 species of canine tick-borne pathogens are present in India. In this study the most prevalent canine TBD pathogen was Hepatozoon canis, and Rhipicephalus ticks were the most common arthropod vectors identified in Delhi and Mumbai. PCR is more sensitive in detecting blood pathogens compared with microscopic blood film examination. Co-infections between pathogens are common in dogs in India and this warrants increased awareness among veterinary practitioners.

\section{Acknowledgements}

Financial support for this study was provided by Bayer Animal Health. We gratefully thank our collaborators; Vets Beyond Borders, Jeevaashram,

Krishnaashram and In Defense of Animal for their help with the fieldwork. Special thanks to; Lyn Knott for her help with tick identification, Brian Bynon and Mark Roper for their help with the slide staining process and Myat Kyaw-tanner for her help with molecular methods. PhD scholarship support for Puteri Azaziah Megat Abd Rani is provided by The Ministry of Higher 
Education, Malaysia. Publication of this thematic series has been sponsored by Bayer Animal Health $\mathrm{GmbH}$.

\section{Author details}

${ }^{1}$ School of Veterinary Science, The University of Queensland, Gatton, Queensland, Australia. 'School of Veterinary and Biomedical Sciences, Murdoch University, Western Australia. ${ }^{3}$ Bombay Veterinary College, Parel, Mumbai, India. ${ }^{4}$ Faculty of Veterinary Medicine, Universiti Putra Malaysia, Malaysia.

\section{Authors' contributions}

PAMAR was involved in all phases of the study, including sampling and data collection, laboratory work, data analysis, intellectual interpretation, and writing the manuscript. RJT designed the study project, supervised the study, and was involved in sampling, field data collection, intellectual interpretation and critical revision of the manuscript for publication. PJI, MG and GTC supervised the study and were involved in intellectual interpretation and critical revision of the manuscript for publication. All authors read and approved the final manuscript.

\section{Competing interests}

The authors declare that they have no competing interests.

Received: 14 February 2011 Accepted: 19 July 2011

Published: 19 July 2011

\section{References}

1. Megat Abd Rani PA, Irwin P, Gatne ML, Coleman G, Traub R: Canine vectorborne diseases in India: a review of literature and identification of existing knowledge gap. Parasit Vectors 2010, 3:28.

2. Homer MJ, Aguilar-Delfin I, Telford SR III, Krause PJ, Persing DH: Babesiosis. Clin Microbiol Rev 2000, 13:451-469.

3. Nakaghi ACH, Machado RZ, Costa MT, André MR, Baldani CD: Canine ehrlichiosis: clinical, hematological, serological and molecular aspects. Ciênc Rural 2008, 38:766-770.

4. Harrus $S$, Waner T: Diagnosis of canine monocytotropic ehrlichiosis (Ehrlichia canis): An overview. Vet J 2010, 187:292-296.

5. Shaw SE, Day MJ, Birtles RJ, Breitschwerdt EB: Tick-borne infectious diseases of dogs. Trends Parasitol 2001, 17:74-80.

6. Sundar N, Balachandran C, Senthivelan A: Incidence of Babesia gibsoni infection in dogs in Tamil Nadu. J Vet Parasitol 2004, 18(1):79-80.

7. Chaudhuri S: Studies on clinico-therapeutic aspects of babesiosis in dogs. M.V.SC. thesis Indian Veterinary Research Institute; 2006.

8. Chaudhuri S, Varshney JP: Clinical management of babesiosis in dogs with homeopathic Crotalus horridus 200C. Homeopathy 2007, 96:90-94.

9. Anderson BE, Dawson JE, Jones DC, Wilson KH: Ehrlichia chaffeensis, a new species associated with human ehrlichiosis. J Clin Microbiol 1991, 29:2838-2842.

10. Irwin PJ, Jefferies R: Arthropod-transmitted diseases of companion animals in Southeast Asia. Trends Parasitol 2004, 20:27-34.

11. Juyal PD, Kalra IS, Singhla LD: Prevalence of haemoprotozoans in domestic animals in Punjab. 6th National congress of Veterinary Parasitology 1994

12. Samaradni D, Maske DK, Kolte SW, Shinde PN: Ehrlichiosis in dogs in Nagpur. J Vet Parasitol 2003, 17:165-166.

13. Mallapur SS: Studies of ehrlichiosis in dogs of Mumbai. M.V.SC. thesis Konkan Krishi Vidyapeeth, Dapoli, Maharashtra; 2002.

14. Lakshmanan B, John L, Gomathinayagam S, Dhinakarraj G: Molecular detection of Ehrlichia canis from blood of naturally infected dogs in India. Veterinarski Arhiv 2007, 77:307.

15. Baneth G, Mathew JS, Shkap V, Macintire DK, Barta JR, Ewing SA: Canine hepatozoonosis: two disease syndromes caused by separate Hepatozoon spp. Trends Parasitol 2003, 19:27-31.

16. Baneth GAD, Samish M, Alekseev E, Aroch I, Shkap V: Transmission of Hepatozoon canis to dogs by naturally-fed or percutaneously-injected Rhipicephalus sanguineus ticks. J Parasitol 2001, 87:606-611.

17. Pawar SD, Gatne ML: Some haematological and biochemical profiles in canine hepatozoonosis. J Vet Parasitol 2005, 19(2):171-172.
18. Gupta MP, Nauriyal DC, Juyal PD, Kalra IS, Khahra SS, Mohan R: Therapeutic trials of Hepatozoon canis infection in dogs. Indian Vet J 1994, 71:1221-1221.

19. Sharma RL, Ranga Rao GSC, Varshney JP: Parasitic diseases of canines - An overview. Int J Anim Sci 1997, 12:231-244.

20. Baneth G, Weigler B: Retrospective case-control study of hepatozoonosis in dogs in Israel. J Vet Intern Med 1997, 11:365-370.

21. Baneth GAD: Canine hepatozoonosis - Two different diseases. 29th World Small Animal Veterinary Association World Congress Proceedings; Rhodes, Greece 2004

22. Mylonakis ME, Koutinas AF, Baneth G, Polizopoulou Z, Fytianou A: Mixed Ehrlichia canis, Hepatozoon canis, and presumptive Anaplasma phagocytophilum infection in a dog. Vet Clin Path 2004, 33:249-251.

23. Bowman D, Little SE, Lorentzen L, Shields J, Sullivan MP, Carlin EP. Prevalence and geographic distribution of Dirofilaria immitis, Borrelia burgdorferi, Ehrlichia canis, and Anaplasma phagocytophilum in dogs in the United States: Results of a national clinic-based serologic survey. Vet Parasitol 2009, 160:138-148.

24. Gaunt SD, Beall MJ, Stillman BA, Lorentzen L, Diniz PPVP, Chandrashekar R, Breitschwerdt EB: Experimental infection and co-infection of dogs with Anaplasma platys and Ehrlichia canis: hematologic, serologic and molecular findings. Parasit Vectors 2010, 3:33.

25. Brinson JJ, Messick JB: Use of a plymerase chain reaction assay for detection of Haemobartonella canis in a dog. J Am Vet Med Assoc 2001, 218:1943-1945.

26. Sykes JE, Ball LM, Bailiff NL, Fry MM: 'Candidatus Mycoplasma haematoparvum', a novel small haemotropic mycoplasma from a dog. Int J Syst Evol Microbiol 2005, 55:27-30.

27. Dharaskar SD, Maske DK, Kolte SW, Shinde PN: Haemobartonellosis in dogs and its treatment. J Vet Parasitol 2003, 17:179.

28. Kumar A, Varshney JP: Clinico-haematological and biochemical investigations in dogs concurrently infected with Anaplasma platys and other blood parasites. J Vet Parasitol 2007, 21:43-45.

29. Megat Abd Rani PA, Irwin P, Gatne M, Coleman G, Mclnnes L, Traub R: A survey of canine filarial diseases of veterinary and public health significance in India. Parasit Vectors 2010, 3:30.

30. Macpherson CN, Meslin FX, Wandeler Al: Dogs, Zoonoses and Public Health Anthony Rowe Limited, Eastbourne; 2000.

31. Walker AR, Bouattour A, Camicas JL, Estrada-Peña A, Horak IG, Latif AA Pegram RG, Preston PM: Ticks of domestic animals in Africa: a guide to identification of species Edinburgh: Bioscience Reports; 2007.

32. Mawby DI, Bartges JW, d'Avignon A, Laflamme DP, Moyers TD, Cottrell T: Comparison of Various Methods for Estimating Body Fat in Dogs. J Am Anim Hosp Assoc 2004, 40:109-114.

33. Vaden SL, Knoll J, Smith FWK, Tilley LP: Blackwell's Five-minute Veterinary Consult Laboratory Tests and Diagnostic Procedures: Canine and Feline. Wiley-Blackwell; 2009.

34. Jefferies R, Ryan UM, Irwin PJ: PCR-RFLP for the detection and differentiation of the canine piroplasm species and its use with filter paper-based technologies. Vet Parasitol 2007, 144:20-27.

35. Wen B, Rikihisa Y, Mott JM, Greene R, Kim HY, Zhi N, Couto GC, Unver A, Bartsch R: Comparison of nested PCR with immunofluorescent-antibody assay for detection of Ehrlichia canis infection in dogs treated with doxycycline. J Clin Microbiol 1997, 35:1852-1855.

36. Gal A, Loeb E, Yisaschar-Mekuzas Y, Baneth G: Detection of Ehrlichia canis by PCR in different tissues obtained during necropsy from dogs surveyed for naturally occurring canine monocytic ehrlichiosis. Vet J 2008, 175:212-217

37. Motoi $Y$, Satoh H, Inokuma H, Kiyuuna T, Muramatsu Y, Ueno H, Morita C: First detection of Ehrlichia platys in dogs and ticks in Okinawa, Japan. Microbiol Immunol 2001, 45:89-91.

38. Rubini AS, Paduan KdS, Cavalcante GG, Ribolla PEM, O'Dwyer LH: Molecular identification and characterization of canine Hepatozoon species from Brazil. Parasitol Res 2005, 97:91-93.

39. Criado-Fornelio A, Martinez-Marcos A, Buling-Saraña A, Barba-Carretero JC: Presence of Mycoplasma haemofelis, Mycoplasma haemominutum and piroplasmids in cats from southern Europe: a molecular study. Vet Microbiol 2003, 93:307-317. 
40. Hosmer DW, Lemeshow S, Wiley J, InterScience W: Applied logistic regression New York: Wiley; 1989

41. Frankena K, Graat EAM: Application of quantitative methods in veterinary epidemiology Wageningen: Wageningen Pers; 1997, 137-178.

42. Heath ACG: The temperature and humidity preferences of Haemaphysalis longicornis, Ixodes holocyclus and Rhipicephalus sanguineus (ixodidae): Studies on engorged larvae. Int I Parasitol 1981, 11:169-175.

43. Yano Y, Shiraishi S, Uchida TA: Effects of temperature on development and growth in the tick, Haemaphysalis longicornis. Exp Appl Acarol 1987, 3:73-78.

44. Sharma BD: Medical \& veterinary arthropod - disease ecology New Delhi: APH Publishing; 1993.

45. Shimada $Y$, Beppu T, Inokuma H, Okuda M, Onishi T: Ixodid tick species recovered from domestic dogs in Japan. Med Vet Entomol 2003, 17:38-45.

46. Ghosh S, Bansal GC, Gupta SC, Ray D, Khan MQ, Irshad H, Shahiduzzaman M, Seitzer U, Ahmed JS: Status of tick distribution in Bangladesh, India and Pakistan. Parasitol Res 2007, 101:207-216.

47. Uilenberg G: Babesia-A historical overview. Vet Parasitol 2006, 138:3-10.

48. Kordick SK, Breitschwerdt EB, Hegarty BC, Southwick KL, Colitz CM, Hancock SI, Bradley JM, Rumbough R, Mcpherson JT, MacCormack JN: Coinfection with multiple tick-borne pathogens in a Walker Hound Kennel in North Carolina. J Clin Microbiol 1999, 37:2631-2638.

49. Yabsley MJ, McKibben J, Macpherson CN, Cattan PF, Cherry NA, Hegarty BC, Breitschwerdt EB, O'Connor T, Chandrashekar R, Paterson T, et al: Prevalence of Ehrlichia canis, Anaplasma platys, Babesia canis vogeli, Hepatozoon canis, Bartonella vinsonii berkhoffii, and Rickettsia spp. in dogs from Grenada. Vet Parasitol 2008, 151:279-285.

50. Zuk M, McKean KA: Sex differences in parasite infections: Patterns and processes. Int J Parasitol 1996, 26:1009-1024.

51. Roberts CW, Walker W, Alexander J: Sex-associated hormones and immunity to protozoan parasites. Clin Microbiol Rev 2001, 14:476-488.

52. Kirkpatrick CE: Epizootiology of endoparasitic infections in pet dogs and cats presented to a veterinary teaching hospital. Vet Parasitol 1988, 30:113-124.

53. Irwin PJ, Hutchinson GW: Clinical and pathological findings of Babesia infection in dogs. Aust Vet J 1991, 68:204-209.

54. Eddlestone SM, Diniz P, Neer TM, Gaunt SD, Corstvet R, Cho D, Hosgood G, Hegarty B, Breitschwerdt EB: Doxycycline clearance of experimentally induced chronic Ehrlichia canis infection in dogs. J Vet Intern Med 2007, 21:1237-1242

doi:10.1186/1756-3305-4-141

Cite this article as: Abd Rani et al:: A survey of canine tick-borne

diseases in India. Parasites \& Vectors 2011 4:141.

\section{Submit your next manuscript to BioMed Central and take full advantage of:}

- Convenient online submission

- Thorough peer review

- No space constraints or color figure charges

- Immediate publication on acceptance

- Inclusion in PubMed, CAS, Scopus and Google Scholar

- Research which is freely available for redistribution

Submit your manuscript at www.biomedcentral.com/submit 